\title{
A danger of induction of Brugada syndrome during pill-in-the-pocket therapy for paroxysmal atrial fibrillation
}

This article was published in the following Dove Press journal:

Drug, Healthcare and Patient Safety

24 August 2010

Number of times this article has been viewed

\section{Yoshiyasu Aizawa \\ Tomohiro Matsuhashi \\ Toshiaki Sato \\ Seiji Takatsuki \\ Keiichi Fukuda}

Division of Cardiology, Keio University School of Medicine, Tokyo, Japan
Correspondence:Yoshiyasu Aizawa Division of Cardiology, Keio University School of Medicine, 35 Shinanomachi, Shinjuku-ku, Tokyo 160-8582, Japan Tel +8I-3-5363-3793

Fax +8I-3-3353-2502

Email yoshiyaaizawa-circ@umin.ac.jp
Abstract: Rhythm control therapy by sodium channel blockers is widely performed for the treatment of paroxysmal atrial fibrillation. Here, we present a case of acquired Brugada syndrome by pill-in-the-pocket treatment using pilsicainide. It is important that this therapy should be applied only after confirming the drug safety to the patients.

Keywords: syncope, sudden death, drug, rhythm control, pilsicainide, atrial flutter

\section{Case report}

A 62-year-old male was transferred to the emergency department due to presyncopal attacks developed after taking pilsicainide. The patient has history of paroxysmal atrial fibrillation and stroke and was treated by cibenzoline $300 \mathrm{mg} /$ day in combination with adequate anticoagulation. Since his atrial fibrillation could not be suppressed by cibenzoline alone, his home doctor prescribed additional pilsicainide of $100 \mathrm{mg}$ for pill-in-the-pocket treatment. This was a first attempt of the pill-in-the-pocket treatment for this patient. His electrocardiography (ECG) on arrival shows 2 to 1 atrial flutter, interventricular conduction disturbance, and coved-type ST segment elevation in leads V1-2 consistent with type I Brugada $\mathrm{ECG}^{1}$ (Figure 1). His previous ECG taken during daily cibenzoline treatment did not show these abnormalities (Figure 2). His serum electrolyte and renal function were normal. Antiarrhythmic drugs were terminated after admission and the ECG returned normal and his clinical course was uneventful. Based on the ECG findings on admission, there are 2 possible causes of the presyncopal attacks in this patient. One possibility is due to nonsustained ventricular fibrillation which was associated with Brugada syndrome, and another possibility is 1 to 1 atrio-ventricular conduction during the atrial flutter. Sodium channel blockers are now widely used for rhythm control therapy for paroxysmal atrial fibrillation. ${ }^{2}$ However, physicians must care for the side effects. The class Ic drug can unmask Brugada syndrome or induce atrial flutter called "Ic flutter". The pill-in-the-pocket treatment for atrial fibrillation is recognized as safe and effective therapy for the rhythm control for the atrial fibrillation. ${ }^{3}$ It is important that this therapy should be applied after confirming the drug safety to the patients. 


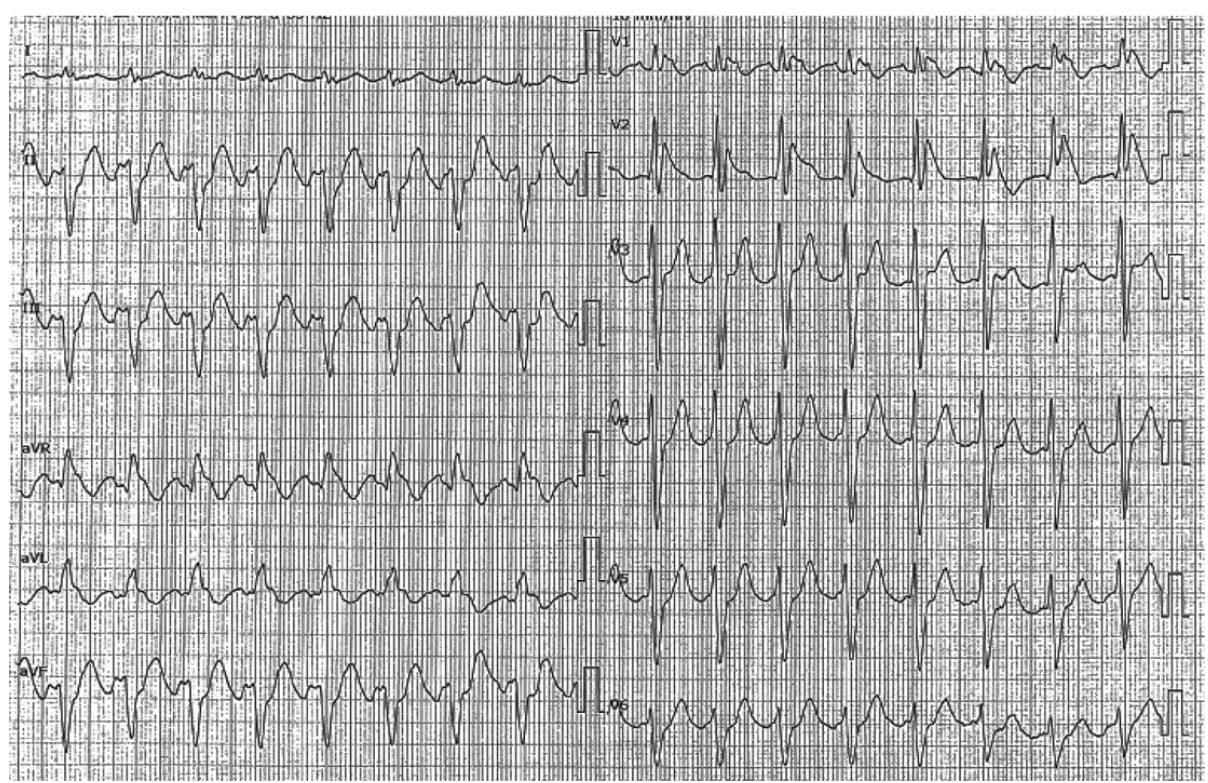

Figure I Electrocardiography on admission.

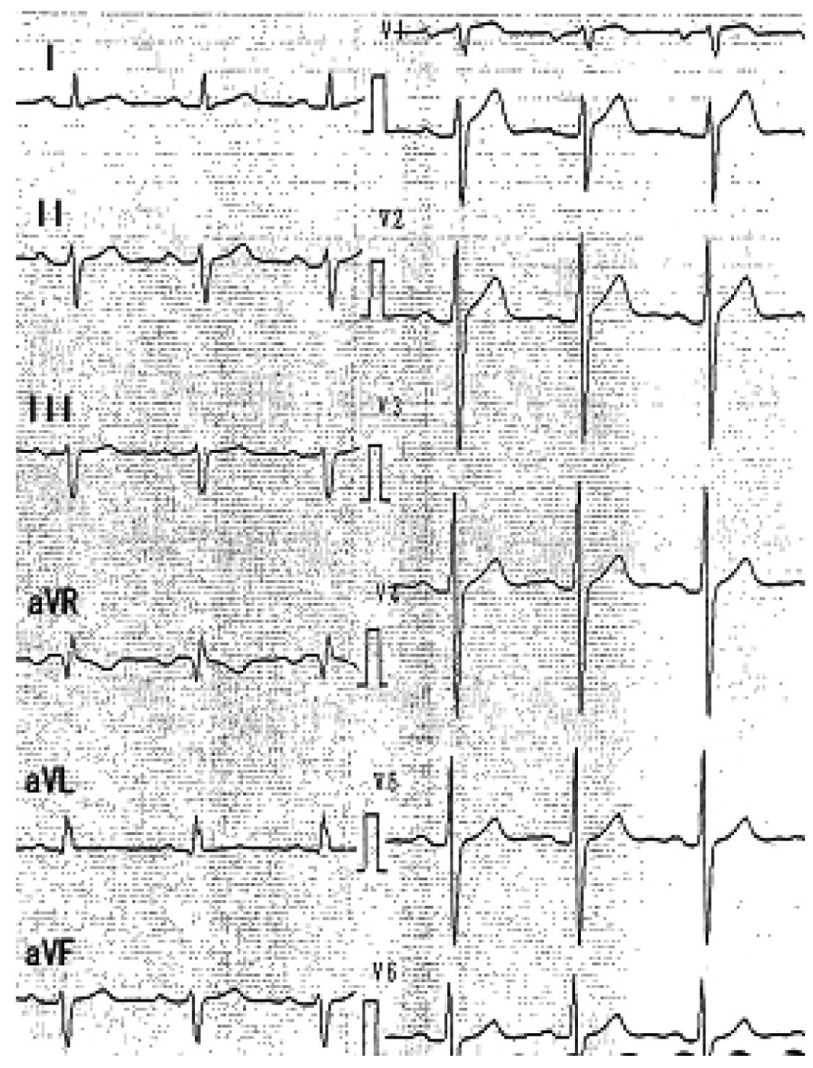

Figure 2 Previous electrocardiography taken during daily cibenzoline alone.

\section{Acknowledgment}

We thank Jeffrey Annis for his linguistic advice.

\section{Disclosure}

The authors report no conflicts of interest in this work.

\section{References}

1. Antzelevitch C, Brugada P, Borggrefe M, et al. Brugada syndrome: report of the second consensus conference: endorsed by the Heart Rhythm Society and the European Heart Rhythm Association. Circulation. 2005; 111(5):659-670.

2. Guidelines for Pharmacotherapy of Atrial Fibrillation (JCS 2008). Circ J. 2008;72 Suppl IV:1581-1638. (Japanese).

3. Alboni P, Botto GL, Baldi N, et al. Outpatient treatment of recent-onset atrial fibrillation with the pill-in-the-pocket approach. $N$ Engl J Med. 2004;351:2384-2391.
Drug, Healthcare and Patient Safety

\section{Publish your work in this journal}

Drug, Healthcare and Patient Safety is an international, peer-reviewed open-access journal exploring patient safety issues in the healthcare continuum from diagnostic and screening interventions through to treatment, drug therapy and surgery. The journal is characterized by the rapid reporting of reviews, original research, clinical, epidemiological and

\section{Dovepress}

post-marketing surveillance studies, risk management, health literacy and educational programs across all areas of healthcare delivery. The manuscript management system is completely online and includes a very quick and fair peer-review system. Visit http://www.dovepress.com/ testimonials.php to read real quotes from published authors. 